Article

\title{
Simultaneous Monitoring of the Evolution of Chemical Parameters in the Fermentation Process of Pineapple Fruit Wine Using the Liquid Probe for Near-Infrared Coupled with Chemometrics
}

\author{
Sumaporn Kasemsumran ${ }^{1, * \mathbb{D}}$, Antika Boondaeng ${ }^{2} \mathbb{D}$, Kraireuk Ngowsuwan ${ }^{1}$, Sunee Jungtheerapanich ${ }^{1}$, \\ Waraporn Apiwatanapiwat $^{2}\left(\mathbb{D}\right.$, Phornphimon Janchai ${ }^{2}$, Jiraporn Meelaksana ${ }^{2}$ and Pilanee Vaithanomsat ${ }^{2} \mathbb{C}$ \\ 1 Laboratory of Non-Destructive Quality Evaluation of Commodities, Kasetsart Agricultural and \\ Agro-Industrial Product Improvement Institute (KAPI), Kasetsart University, Bangkok 10900, Thailand; \\ aapkrn@ku.ac.th (K.N.); aapsnj@ku.ac.th (S.J.) \\ 2 Laboratory of Enzyme and Microbiology, KAPI, Kasetsart University, Bangkok 10900, Thailand; \\ aapakb@ku.ac.th (A.B.); aapwpa@ku.ac.th (W.A.); aappmj@ku.ac.th (P.J.); aapjom@ku.ac.th (J.M.); \\ aappln@ku.ac.th (P.V.) \\ * Correspondence: aapspk@ku.ac.th; Tel.: +66-02-942-8600
}

check for updates

Citation: Kasemsumran, S.; Boondaeng, A.; Ngowsuwan, K.; Jungtheerapanich, S.;

Apiwatanapiwat, W.; Janchai, P.; Meelaksana, J.; Vaithanomsat, P. Simultaneous Monitoring of the Evolution of Chemical Parameters in the Fermentation Process of Pineapple Fruit Wine Using the Liquid Probe for Near-Infrared Coupled with Chemometrics. Foods 2022, 11, 377. https://doi.org/ $10.3390 /$ foods 11030377

Received: 25 December 2021

Accepted: 26 January 2022

Published: 28 January 2022

Publisher's Note: MDPI stays neutral with regard to jurisdictional claims in published maps and institutional affiliations.

Copyright: (C) 2022 by the authors. Licensee MDPI, Basel, Switzerland. This article is an open access article distributed under the terms and conditions of the Creative Commons Attribution (CC BY) license (https:// creativecommons.org/licenses/by/ $4.0 /)$

\begin{abstract}
This study used Fourier transform-near-infrared (FT-NIR) spectroscopy equipped with the liquid probe in combination with an efficient wavelength selection method named searching combination moving window partial least squares (SCMWPLS) for the determination of ethanol, total soluble solids, total acidity, and total volatile acid contents in pineapple fruit wine fermentation using Saccharomyces cerevisiae var. burgundy. Two fermentation batches were produced, and the NIR spectral data of the calibration samples in the wavenumber range of $11,536-3952 \mathrm{~cm}^{-1}$ were obtained over ten days of the fermentation period. SCMWPLS coupled with second derivatives searched and optimized spectral intervals containing useful information for building calibration models of four parameters. All models were validated by test samples obtained from an independent fermentation batch. The SCMWPLS models showed better predictions (the lowest value of prediction error and the highest value of residual predictive deviation) with acceptable statistical results (under confidence limits) among the results achieved by using the whole region. The results of this study demonstrated that FT-NIR spectroscopy using a liquid probe coupled with SCMWPLS could select the optimized wavelength regions while reducing spectral points and increasing accuracy for simultaneously monitoring the evolution of four chemical parameters in pineapple fruit wine fermentation.
\end{abstract}

Keywords: near-infrared spectroscopy; searching combination moving window partial least squares; pineapple; fruit wine; fermentation; liquid probe

\section{Introduction}

Pineapple (Ananas comosus L.) originates from South America and is one of the most favoured subtropical fruits cultivated (above 20\% of the tropical fruit generated in the world) and consumed worldwide. It is a drought-tolerant plant with good taste [1]. The top three pineapple producers worldwide in 2019 were reported to be Costa Rica $\left(3328.10 \times 10^{3}\right.$ metric tons), the Philippines $\left(2747.86 \times 10^{3}\right.$ metric tons), and Brazil $\left(2426.53 \times 10^{3}\right.$ metric tons), while Thailand is ranked seventh $\left(1679.67 \times 10^{3}\right.$ metric tons) [2] The fruit is frequently consumed fresh and used in the food industry (canned fruit, jam, and concentrated juice) for alcoholic beverage production [3] and fibre production [1]. In Thailand, pineapple wine is popularly consumed because of its unique taste, colour, and flavour. The consumption trend of wine made from pineapple and other fruits is likely to increase, especially among health-conscious consumers, because fruit wines are also nutritious and healthy $[4,5]$. 
Wine is an undistilled alcoholic beverage obtained from grapes or other fruits and plants, sugar, innate microorganisms, and yeast in suitable proportions [5,6]. Some sweet wine usually takes about ten days or more for the fermentation process before complete sugar conversion [7]. Wine composition is mainly composed of water and ethanol (97\% $w / w$ of the constituents in wine), which defines wine properties together with the viscosity, polarity, and solubility [8,9]. The other components $(3 \% w / w$ of the constituents in wine) of phenolic compounds, sugars, glycerol, proteins, amino acids, organic acids, and inorganic compounds deliver the perceived colour, aroma, and flavour of wine, including sensory attributes (astringency and bitterness) that affect the quality and consumer preference [10]. Fermentation is an essential step in the production process owing to various physicochemical changes that occur during this step [11]. The wine industry requires analytical tools to rapidly determine components of fruit juices and wines for significant decision making during fermentation. These tools must ensure speed, simplicity, low or no sample preparation and destruction, and unused reagents or solvents [12]. Gas chromatography or highperformance liquid chromatography is broadly used for intensive quality analysis of wine. However, these techniques are time-consuming, laborious, and complicated methods [13]. In contrast, vibrational spectroscopy techniques have increased widespread acceptance and utilisation because they are non-destructive, fast, and suitable for routine analysis [14]. NIR spectroscopy is a vibrational spectroscopic technique, which is a promising technique for multicomponent analysis in wine fermentation. The NIR region is associated with the overtone and combination bands of the fundamental molecular vibrations of the $\mathrm{OH}, \mathrm{CH}$, and NH functional groups [15-17] Therefore, most components show absorption in the NIR region. However, it was found that studies using infrared (IR) spectroscopy to monitor wine fermentation techniques were more widely reported than NIR techniques [11,18], since NIR absorption bands are far weaker than IR absorption bands and a number of bands overlap each other due to overtone and combination modes [15-17]. Especially for highly complex samples such as fermented fruit wine, many NIR bands overlap each other in their NIR spectra.

In order to extract useful information from such complex NIR spectra of fermented fruit wine samples, chemometric methods are employed for spectral analysis. The proposed NIR quantitative determination of the multiple components for monitoring the wine fermentation process is shown in Table 1. In the previously published reports, the classical partial least squares (PLS) method was generally employed in the applications (Table 1). Several spectral preprocessings, such as baseline correction [19], first derivative (FD) [19-23], second derivative (SD) [20,21,23], detrending (DT) [19], eliminating the constant offset (ECO) [20], min-max normalization (MMN) [20,21], multiplicative scattering correction (MSC) [19-23]. Savitzky-Golay (SG) smoothing [19], standard normal variate (SNV) [19], stepwise regression analysis (SRA) [22], straight-line subtraction (SLS) [21], minus a straight line (MSL) [20], support vector machine (SVM) [19], and vector normalization (VN) [20,21] were applied. There was also a report for the use of wavelength selection methods, namely regression coefficient analysis (RCA)-PLS, the successive projection algorithm (SPA)-PLS, interval (i)-PLS, and the genetic algorithm (GA)-PLS with the model developments, in the prediction of ethanol and total acid contents during Chinese rice wine fermentation. The prediction result of using the wavelength selection methods of RCA-SVM-PLS (RMSEP for ethanol $=2.60 \mathrm{~g} \mathrm{~L}^{-1}$ ) and GA-SVM-PLS (RMSEP for total acid $=0.10 \mathrm{~g} \mathrm{~L}^{-1}$ ) provided better predictive performance than using the full-spectrum SVM-PLS (RMSEP for ethanol $=4.94 \mathrm{~g} \mathrm{~L}^{-1}$ and for total acid $=0.14 \mathrm{~g} \mathrm{~L}^{-1}$ ) [19]. 
Table 1. Literature reviews of the applications of NIR or VIS-NIR spectroscopy for quantitative analysis of constituents in wine during the fermentation process.

\begin{tabular}{|c|c|c|c|c|c|c|}
\hline Sample & $\begin{array}{l}\text { VIS-NIR or } \\
\text { NIR Range } \\
\left(\mathrm{cm}^{-1}\right)\end{array}$ & $\begin{array}{l}\text { Measurement } \\
\text { Mode }\end{array}$ & $\begin{array}{c}\text { Sample } \\
\text { Preparation }\end{array}$ & $\begin{array}{l}\text { Chemometric } \\
\text { Method }\end{array}$ & Analyst & $\begin{array}{c}\text { RMSEP or } \\
\text { a RMSECV or } \\
\text { b } \text { REP or }{ }^{c} \text { SECV }\end{array}$ \\
\hline \multirow{4}{*}{$\begin{array}{l}\text { Apple wine } \\
\text { [20] }\end{array}$} & \multirow{4}{*}{$12,000-4000$} & \multirow{4}{*}{$\begin{array}{l}\text { Transmission; } \\
\text { Quartz cuvette }\end{array}$} & \multirow{4}{*}{$\begin{array}{l}\text { Centrifugation } \\
\text { and filtration }\end{array}$} & \multirow{4}{*}{ PLS } & Soluble solid content & $0.60 \%$ \\
\hline & & & & & $\mathrm{pH}$ & 0.08 \\
\hline & & & & & Total acidity & $0.02{\mathrm{~g} 100 \mathrm{~mL}^{-1}}^{-1}$ \\
\hline & & & & & Total ester content & $0.10 \mathrm{~g} \mathrm{~L}^{-1}$ \\
\hline \multirow{2}{*}{$\begin{array}{l}\text { Apple wine } \\
\text { [21] }\end{array}$} & \multirow{2}{*}{$12,000-4000$} & \multirow{2}{*}{$\begin{array}{l}\text { Transflection; } \\
\text { Liquid probe }\end{array}$} & \multirow{2}{*}{ Centrifugation } & \multirow{2}{*}{ PLS } & Alcohol strength & $4.25 \mathrm{~mL} \mathrm{~L}^{-1}$ \\
\hline & & & & & Titratable acidity & $0.21 \mathrm{~g} \mathrm{~L}^{-1}$ \\
\hline $\begin{array}{c}\text { Jujube wine } \\
{[22]}\end{array}$ & $10,526-6060$ & $\begin{array}{l}\text { Transmission; } \\
\text { Quartz cuvette }\end{array}$ & Filtration & PLS & Alcohol & a $0.70 \%$ \\
\hline \multirow{3}{*}{$\begin{array}{l}\text { Red wine } \\
\text { [13] }\end{array}$} & \multirow{3}{*}{$25,000-4000$} & \multirow{3}{*}{$\begin{array}{l}\text { Transmission; } \\
\text { Quartz cuvette }\end{array}$} & \multirow{3}{*}{ Centrifugation } & \multirow{3}{*}{ PLS } & Malvidin-3-glucoside & ${ }^{\mathrm{c}} 17.50-31.50 \mathrm{mg} \mathrm{L}^{-1}$ \\
\hline & & & & & Pigmented polymers & c $3.20-26.80 \mathrm{mg} \mathrm{L}^{-1}$ \\
\hline & & & & & Tannins & ${ }^{\mathrm{c}} 49.10-131.20 \mathrm{mg} \mathrm{L}^{-1}$ \\
\hline \multirow{2}{*}{$\begin{array}{l}\text { Rice wine } \\
\text { [19] }\end{array}$} & \multirow{2}{*}{$10,000-4000$} & \multirow{2}{*}{$\begin{array}{l}\text { Transmission; } \\
\text { Quartz cuvette }\end{array}$} & \multirow{2}{*}{ Centrifugation } & RCA-SVM-PLS & Ethanol & $2.60 \mathrm{~g} \mathrm{~L}^{-1}$ \\
\hline & & & & GA-SVM-PLS & Total acid & $0.10 \mathrm{~g} \mathrm{~L}^{-1}$ \\
\hline \multirow{2}{*}{$\begin{array}{l}\text { White wine } \\
\text { [23] }\end{array}$} & \multirow{2}{*}{$14,285-9434$} & \multirow{2}{*}{$\begin{array}{l}\text { Transmission; } \\
\text { Quartz cuvette }\end{array}$} & \multirow{2}{*}{ Filtration } & \multirow{2}{*}{ PLS } & Volumic mass & ${ }^{\mathrm{a}} 4.18 \mathrm{~g}\left(\mathrm{dm}^{3}\right)^{-1}$ \\
\hline & & & & & Reducing sugars & a $10.35 \mathrm{~g} \mathrm{~L}^{-1}$ \\
\hline
\end{tabular}

RMSEP $=$ Root mean square error of prediction; ${ }^{a}$ RMSECV $=$ Root mean square error of cross validation; ${ }^{b}$ SEP $=$ Standard error of prediction; ${ }^{\mathrm{c}} \mathrm{SECV}=$ Standard error of cross validation; RCA = Regression coefficient analysis; $\mathrm{SVM}=$ Support vector machine; GA = Genetic algorithm .

Accordingly, the wavelength selection method is a crucial tool for searching the relevant information to improve the quality of prediction models for NIR analysis in wine fermentation. Advanced chemometrics, namely searching combination moving window partial least squares (SCMWPLS) [24], has been proposed to improve the performance of a PLS model. It functions as a spectral selection method to locate and optimize informative regions through spectra. The ability of calibration models can be improved by building the PLS models using the optimized informative regions found by SCMWPLS. The potentials of SCMWPLS were demonstrated and appeared in previously published reports [24-27]. However, no reports appear to have been published on the quantification of multiple components in pineapple fruit wine during the fermentation process using NIR spectroscopy in combination with the wavelength selection method. Therefore, the objectives of this study were (1) to investigate the feasibility of using NIR spectroscopy coupled with SCMWPLS in finding and optimizing informative spectral regions for simultaneous monitoring of the evolution of ethanol, total soluble solids (TSS), total acidity (TA), and total volatile acids (TVA) in pineapple fruit wine during fermentation, and (2) the use of an NIR liquid probe for immediate monitoring without sample preparation.

\section{Materials and Methods}

\subsection{Pineapple Wine}

\subsubsection{Yeast Culture Preparation}

Saccharomyces cerevisiae var. burgundy, the primary yeast for general wine fermentation used in this study, was obtained from the Institute of Food Research and Product Development (IFRPD), Kasetsart University, Thailand. Yeast strains were activated on YPD agar for 24 to $48 \mathrm{~h}$ before use. An inoculum of $5 \%\left(\mathrm{~V} \mathrm{~V}^{-1}\right)$ was prepared by mixing pineapple juice with yeast colonies $\left(1 \times 10^{5} \mathrm{CFU} \mathrm{mL}^{-1}\right)$ for an incubation time of $24 \mathrm{~h}$ as a starter. 


\subsubsection{Preparation of Pineapple Must}

Pineapple samples at the ripe stage were purchased from a local market in Bangkok, Thailand. They were cleaned, peeled, and crushed. The ratio of pineapple juice to water was adjusted to obtain a 2:1 optimum ratio. The initial sugar concentration of the pineapple juice was adjusted to $25^{\circ}$ Brix by adding sucrose. Potassium metabisulfite $\left(\mathrm{K}_{2} \mathrm{~S}_{2} \mathrm{O}_{5}\right)$ was then added for decontamination to achieve a $75-100 \mathrm{mg} \mathrm{L}^{-1}$ final concentration.

\subsubsection{Pineapple Juice Fermentation}

The fermentation of pineapple wine was performed in a polyethylene terephthalate bottle with a working volume of $15 \mathrm{~L}$. Inoculum yeast cultures $\left(5 \% \mathrm{~V} \mathrm{~V}^{-1}\right)$ were used as a starter for wine fermentation in sterile pineapple juice. Fermentation was conducted for ten days at a controlled temperature of $30^{\circ} \mathrm{C}$ using a water bath system. In total, three batches of fermentations were independently performed and employed two batches for calibration development and one batch for testing the predictive performance of the calibration model in this study.

\subsection{NIR Liquid Probe Spectral Acquisition}

A liquid fibre-optic probe (IN271P-02, Bruker Optics GmbH \& Co. KG, Ettlingen, Germany) was used to collect the spectral data of the liquid wine sample in transflection mode. The NIR spectral information obtained using a transflectance probe provided an adequate signal dominating from both transmittance and reflectance information. The probe length was $14 \mathrm{~cm}$, with a fixed optical path length of $2 \mathrm{~mm}$ (slit $1 \mathrm{~mm}$ ). It consisted of fibre bundles with seven fibres in the stainless-steel probe housing with a sapphire window and an immersion probe designed for bubble shedding that is suitable for lab and process applications. The liquid probe was connected to an FT-NIR spectrophotometer (MPA II, Multi-Purpose Analyser, Bruker Optics GmbH \& Co. KG, Ettlingen, Germany) for spectral acquisition between 11,536 and $3952 \mathrm{~cm}^{-1}$, and it was immersed in liquid samples for spectra acquisition. The air spectra were collected as the background for the measurements. For the establishment of the calibration model, a 30-40 mL sample was collected aseptically at the beginning of fermentation $(0 \mathrm{~h})$ and continued with a loop time of 3, 6, and $18 \mathrm{~h}$ every day until $240 \mathrm{~h}$, for NIR scanning and chemical analysis. Before the sampling, the fermented samples in the bottle were randomly stirred by a sterile plastic rod and pipetted into a $50 \mathrm{~mL}$ sterile plastic tube. Each sample was divided for the NIR analysis and chemical analysis. To obtain the NIR information of a sample close to the actual samples as in the fermented bottle, all samples were directly scanned by the liquid probe without further preparation and the sterile plastic tube was used as the holder for the liquid sample. Regarding the acquisition process, the sample variation and light scattering variation were included in this study. After sampling, NIR measurements of the samples were immediately performed at a spectral resolution of $16 \mathrm{~cm}^{-1}$ with an interval of $8 \mathrm{~cm}^{-1}$ and a repeating 32-time scan per one measurement. Therefore, the data of 99 NIR spectral samples were obtained from one batch of the pineapple wine fermentation process $(1$ batch $\times 11$ times $(0 \mathrm{~h}$ and ten days $) \times 3$ sampling times $\times 3$ subsamples $)$. The validation of model performance in NIR analysis was performed using the same process as described earlier, except the NIR spectral acquisition of samples that were measured by immersing the liquid fibre-optic probe in the fermented pineapple wine bottle. Furthermore, the plastic tube was used to cover the fibre line to avoid error from moving while the spectra were collected. The sample temperature was controlled at $30^{\circ} \mathrm{C}$ throughout the experiment. Figure 1 shows the setting of the liquid fibre-optic probe for the NIR measurement of test samples during the fermentation process. 


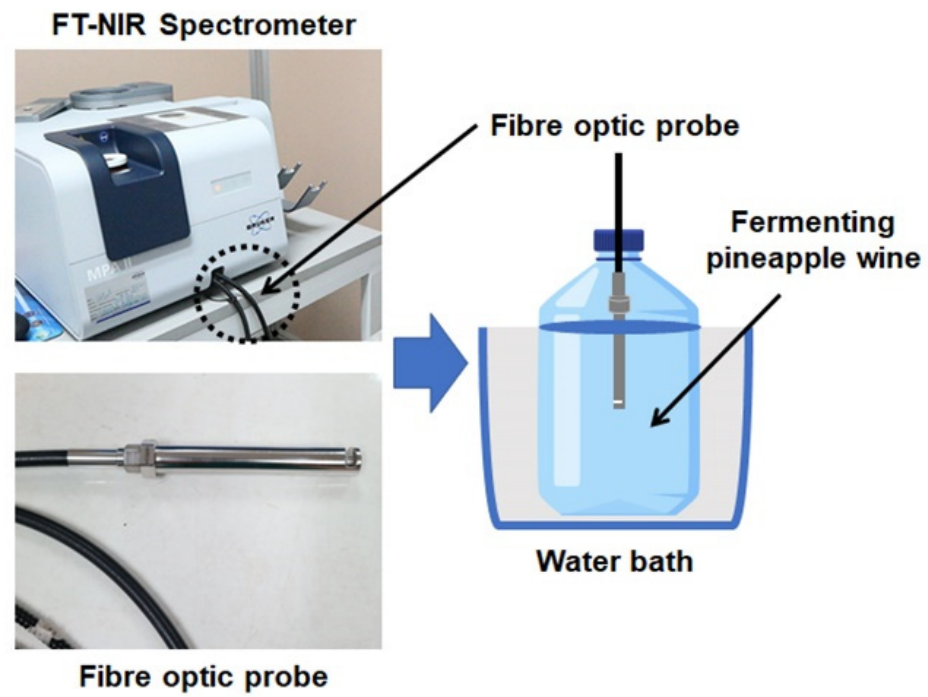

Figure 1. The scheme of the NIR measurement through the fermented bottle using the liquid fibreoptic probe.

2.3. Pineapple Wine Chemical Analysis for Ethanol, Total Soluble Solids, Total Acidity, and Total Volatile Acids Using the Conventional Reference Methods

Four parameters of ethanol, total soluble solids (TSS), total acidity (TA), and total volatile acids (TVA) contents were monitored during fermentation processing and employed as the reference chemical data for NIR model development. For the chemical analysis, the samples were filtrated through the filter paper (No.1, Whatman) before determination as follows: (1) Ethanol concentration was assessed using gas chromatography (Chromosorb-103, GC4000; GL Sciences; Tokyo, Japan) with an HP5 capillary (30 $\mathrm{m} \times 0.32 \mathrm{~mm} \times 0.25 \mu \mathrm{m}$; JW Scientific; Folsom, CA, USA). (2) The TSS content in the sample was determined using a digital refractometer (PAL-1, ATAGO, Tokyo, Japan). (3) TA [28] and (4) TVA [29] were determined as citric acid and acetic acid, respectively, by titration using phenolphthalein as an indicator. For TA analysis, a sample $(10 \mathrm{~mL})$ was pipetted into a $250 \mathrm{~mL}$ Erlenmeyer flask containing $100 \mathrm{~mL}$ of hot distilled water. Phenolphthalein (2-3 drops) was added to the flask and titrated with $0.1 \mathrm{~N} \mathrm{NaOH}$ until a pink colour appeared. TVA is separated from the wine samples by steam distillation before titration using sodium hydroxide $(0.1 \mathrm{~N})$ to obtain the pink end point indicated by the phenolphthalein solution. All measurements were performed in triplicate.

\subsection{NIR Data Analysis}

\subsubsection{Preprocessing Method}

The NIR spectral data were collected using OPUS software (version 8.2: MPA II system, Bruker Optics GmbH \& Co. KG, Ettlingen, Germany) and converted into JCAMP files. After that, the JCAMP files were imported into Unscrambler software (version 9.8: CAMO AS, Trondheim, Norway) and were independently performed without the method of spectral pretreatment (original spectral data) and with the method of second derivatives (SD) based on the Savitzky-Golay model (polynomial order = 2, number of smoothing points $=7$ ) in order to remove the signal variation (spectral offsets and slopes) from light scattering in the fermented samples [15].

\subsubsection{Searching Combination Moving Window Partial Least Squares (SCMWPLS) Analysis}

Two algorithms, moving window partial least squares regression (MWPLSR) [30] and SCMWPLS [24], were employed, respectively, in the calculation procedure. The calculation process of SCMWPLS is described as follows. 


\section{Step 1: MWPLSR Calculation}

In MWPLSR, the calculation starts by building a series of PLS models in a spectral window $\boldsymbol{X}_{i}(m \times h$ matrix $)$ that starts at the $i$ th spectral channel and ends at the $(i+H-1)$ th spectral channel, which moves over the whole spectral region $(m \times n$ matrix $)$. The spectra obtained in the spectral window is a sub-matrix $X_{i}(n \times h$ matrix $)$ containing the $i$ th to the $(i+H-1)$ th columns of the calibration matrix $X$. The PLS- 1 models with different numbers of LV can then be built to relate the spectra in the window to the concentrations of the analyte as follows:

$$
y_{i}=X_{i} b_{i, k}+e_{i, k}
$$

where $b_{i, k}(H \times 1$ vector $)$ is the regression coefficients vector estimated using PLS with $k$ - LV and $e_{i, k}$ is the residue vector obtained with a $k$-LV model. In this study, the window size for MWPLSR and the maximum LVs number were set to 20 spectral points and $10 \mathrm{LVs}$. The mean centred spectra in the whole region of $11,536-3952 \mathrm{~cm}^{-1}$ were applied. To avoid the effect on the residue lines obtained, the window size should be larger than the desired model dimensionality (LVs) and smaller than the spectral regions to be discovered. The window is moved over the whole spectral region. At each position, PLS models with varying LV numbers are built for the calibration samples, and the log of sums of squared residues $(\log (\mathrm{SSR}))$ are calculated with these PLS models and plotted as a function of the window position.

$$
\operatorname{SSR}_{i}=\left(y_{i}-\boldsymbol{X}_{i} \hat{b}_{i}\right)^{t}\left(y_{i}-\boldsymbol{X}_{i} \hat{b}_{i}\right)
$$

This will yield a number of residue lines, with each line associated with the log(SSR) for a certain LV in the corresponding window position. Then, the informative NIR spectral regions were discovered by plotting the residue lines corresponding to 1 to $10 \mathrm{LVs}$ for PLS as a function of the position of the spectral window. A figure containing such residual lines provides information about informative spectral regions where residual lines show low values of SSR.

\section{Step 2: SCMWPLS Calculation}

After the selection of informative regions by MWPLSR, SCMWPLS starts to work for a given informative region with $\mathrm{p}$ spectral points by changing the moving window size $w$ from 1 to $p$. A moving window is moved from the first spectral point to the $(p-w+1)$ th point over the informative region to collect all possible sub-windows for every window size. When $w=1$, moving the window from the first to the end point will collect all possible sub-windows with the window size of one. Similarly, in other cases of $w$, all sub-windows with the size of $w$ may be obtained. Therefore, this algorithm considers all possible spectral intervals in the range of the informative region. For every window, a PLS model with a selected LVs number is constructed, and the root mean square error of the calibration (RMSEC) is calculated. Comparing values of RMSEC for all sub-regions, the sub-region with the smallest value of RMSEC is considered the optimized informative region.

In this study, more than one informative region is suggested by MWPLSR, and the optimized combination of informative regions was performed by using the optimized sub-region as the base region. Next, SCMWPLS is performed for the second informative region, in which one uses the combinations of the base region and one of the possible spectral intervals selected from the second informative region to build PLS models and calculate their RMSEC values. After that, a new base region will be selected, which shows the smallest value of RMSEC. This calculation procedure is repeated to look for another new base region for the next informative region, until the last informative region is reached. After finishing calculations for all informative regions, the final base region is considered as the optimized combination. In SCMWPLS, the maximum LVs number is constrained and the LVs number selected by the validation method must not be larger than the maximum. The LVs number of the PLS model for an informative region can easily be estimated by regressing the spectra in the region against the concentrations. The LVs number is determined to be the number where the root mean square error of calibration (RMSEC) begins to decrease insignificantly with the increase in the LVs number. This LVs number 
is considered the maximum LVs number. All these calculations were carried out using in-house written programs in the MATLAB software (version 2020b: The MathWorks Inc., Natick, MA, USA).

\subsubsection{Calibration Development}

PLS-1 (Unscrambler software) was applied to the spectral regions to develop the calibration models for the quantitative determination of ethanol, TSS, TA, and TVA in samples, simultaneously. The saturated NIR spectral region of $5248-4984 \mathrm{~cm}^{-1}$ was not included in the model developments as this spectral range is beyond the linear response region of the detector $[19,25]$. Two and one fermentation batches for pineapple wine samples were employed as the calibration set $(n=198)$ and test set $(n=99)$, respectively. The full cross-validation method was used to find the optimum number of LVs for PLS by considering the number at which the lowest root mean squares error of cross-validation was obtained, and it increased from the next number $[24,30,31]$. The performances of the established calibration equations were further validated using the test set. To investigate the benefit of SCMWPLS, the PLS prediction results for the calibration models developed by using the spectral regions found by SCMWPLS were compared with those by using the full spectral regions according to the general PLS method.

\subsection{Evaluation of the Predictive Ability of PLS and SCMWPLS Models}

The prediction ability of models built by the whole NIR spectral region and the informative NIR region found by SCMWPLS were investigated and compared on the test set using the coefficient of determination $\left(R^{2}\right)$, root mean square error of calibration (RMSEC), root mean square error of prediction (RMSEP), and residual predictive deviation (RPD). An acceptable NIR model should present high values of $R^{2}$ and RPD and low values of RMSEC and RMSEP. In addition, the accuracy of the best model was evaluated using values of the bias confidence limits $\left(T_{b}\right)$ and the unexplained error confidence limits $\left(T_{\mathrm{UE}}\right)$, following the guidelines for the application of the NIR spectrometer described in ISO 12099 (2017) [32]. This verification method can assess the accepted model performance when the given standard error of prediction (SEP) and bias values fall within the confidence limits. Several earlier reports employed the standard ISO method, which has been detailed previously [33,34]. The statistics employed in this study are defined in Table 2.

Table 2. Summary of statistical computations used to estimate NIR model performance.

\begin{tabular}{|c|c|}
\hline Statistical Terms & Computations \\
\hline Coefficient of determination $\left(R^{2}\right)$ & $R^{2}=\frac{\left(\sum_{i=1}^{n}\left(x_{i}-\bar{x}\right)\left(y_{i}-\bar{y}\right)\right)^{2}}{\sum_{i=1}^{n}\left(x_{i}-\bar{x}\right)^{2} \sum_{i=1}^{n}\left(y_{i}-\bar{y}\right)^{2}}$ \\
\hline $\begin{array}{l}\text { Root mean square error (RMSE) } \\
\text { RMSEC in the calibration set } \\
\text { RMSEP in the test set }\end{array}$ & $\mathrm{RMSE}=\sqrt{\frac{1}{n} \sum_{i=1}^{n}\left(x_{i}-y_{i}\right)^{2}}$ \\
\hline Standard error of prediction (SEP) & $\mathrm{SEP}=\sqrt{\frac{1}{(n-1)} \sum_{i=1}^{n}\left(x_{i}-y_{i}-\mathrm{Bias}\right)^{2}}$ \\
\hline Bias & Bias $=\frac{1}{n} \sum_{i=1}^{n}\left(x_{i}-y_{i}\right)$ \\
\hline Residual predictive deviation (RPD) & $\mathrm{RPD}=\frac{\mathrm{SD}}{\mathrm{RMSEP}}$ \\
\hline Bias confidence limits $\left(T_{b}\right)=$ & $T_{b}= \pm \frac{t_{(1-\alpha / 2)} \times \mathrm{SEP}}{\sqrt{n}}$ \\
\hline Unexplained error confidence limits ( $\left.T_{\mathrm{UE}}\right)$ & $T_{\mathrm{UE}}=S E C \times \sqrt{F_{(\alpha, v, M)}}$ \\
\hline
\end{tabular}




\section{Results and Discussion}

\subsection{Measured Chemical Characteristics of Pineapple Wines during Fermentation by Reference Methods}

The results of the chemical analysis of pineapple wine samples during the process of fermentation are listed in Table 3. The results in a row show the averages of multiple measurements from two sample batches collected in the same day of fermentation. During the fermentation, the samples have an ethanol content of 0.0590 to $10.7592 \%$, TTS in the range of 23.70 to $10.25^{\circ}$ Brix, TA of 0.2925 to $0.4558 \%$, and TVA of 0.0013 to $0.0018 \%$. The concentrations of ethanol, TA, and TVA in the samples increased with days of fermentation. On the other hand, the concentration of TTS in the sample decreased. Among the four analysts, ethanol and TSS values have higher variation than TA and TVA values as shown in Figure 2. As a result, the amount of TSS decreases rapidly because Saccharomyces cerevisiae var. burgundy produces the invertase enzyme that breaks down sucrose into glucose and fructose [35]. Then, glucose is converted into ethanol and carbon dioxide with other enzymes related to Embden-Meyerhof-Panas (EMP). Thus, yeast uses sugar to grow and produce ethanol at the same time (Figure 2A). It can be seen that both of the TA and TVA contents increased slightly during fermentation (Figure 2B). An increase in the acid content of wine during the fermentation period resulted in suitable conditions for yeast growth [36].

Table 4 summarizes the distribution of the ethanol, TSS, TA, and TVA reference values in the samples for calibration and test sets. The content ranges of all chemical reference values in the samples for the calibration set covered those ranges found in the samples for the test set. Consequently, the variability of sample data in both calibration and prediction sets was considered appropriate for developing reliable NIR calibration models for ethanol, TSS, TA, and TVA predictions.

Table 3. The average content of ethanol, total soluble solids, total acidity, and total volatile acids in the samples from two batches of the pineapple wine fermentation process.

\begin{tabular}{ccccc}
\hline Fermentation Day & Ethanol (\%) & Total Soluble Solids $\left({ }^{\circ}\right.$ Brix) & Total Acidity (\%) & Total Volatile Acids (\%) \\
\hline 0 & 0.06 & 23.70 & 0.29 & $1.30 \times 10^{-3}$ \\
1 & 0.40 & 23.17 & 0.32 & $1.30 \times 10^{-3}$ \\
2 & 3.91 & 18.42 & 0.35 & $1.28 \times 10^{-3}$ \\
3 & 5.54 & 15.88 & 0.38 & $1.50 \times 10^{-3}$ \\
4 & 6.74 & 13.87 & 0.39 & $1.67 \times 10^{-3}$ \\
5 & 7.75 & 12.33 & 0.41 & $1.65 \times 10^{-3}$ \\
6 & 8.49 & 11.35 & 0.42 & $1.75 \times 10^{-3}$ \\
8 & 9.06 & 10.83 & 0.44 & $1.80 \times 10^{-3}$ \\
9 & 9.71 & 10.52 & 0.44 & $1.78 \times 10^{-3}$ \\
10 & 10.08 & 10.33 & 0.45 & $1.78 \times 10^{-3}$ \\
\end{tabular}

Table 4. Content distribution of ethanol, total soluble solids, total acidity, and total volatile acids in the calibration set $(n=198)$ and test set $(n=99)$ determined by the reference methods.

\begin{tabular}{cccccc}
\hline Parameters & Sample Set & Minimum & Mean & Maximum & Standard Deviation \\
\hline Ethanol & Calibration & 0.04 & 6.61 & 11.56 & 3.60 \\
$(\%)$ & Test & 0.12 & 6.83 & 10.68 & 3.43 \\
\hline Total soluble solids & Calibration & 10.00 & 14.57 & 24.20 & 4.88 \\
$\left({ }^{\circ}\right.$ Brix $)$ & Test & 10.53 & 14.55 & 23.50 & 4.62 \\
\hline Total acidity & Calibration & 0.29 & 0.40 & 0.48 & 0.05 \\
$(\%)$ & Test & 0.29 & 0.40 & 0.47 & 0.06 \\
\hline Total volatile acids & Calibration & $1.10 \times 10^{-3}$ & $1.60 \times 10^{-3}$ & $1.90 \times 10^{-3}$ & $2.00 \times 10^{-4}$ \\
$(\%)$ & Test & $1.10 \times 10^{-3}$ & $1.60 \times 10^{-3}$ & $1.80 \times 10^{-3}$ & $3.00 \times 10^{-4}$ \\
\hline
\end{tabular}



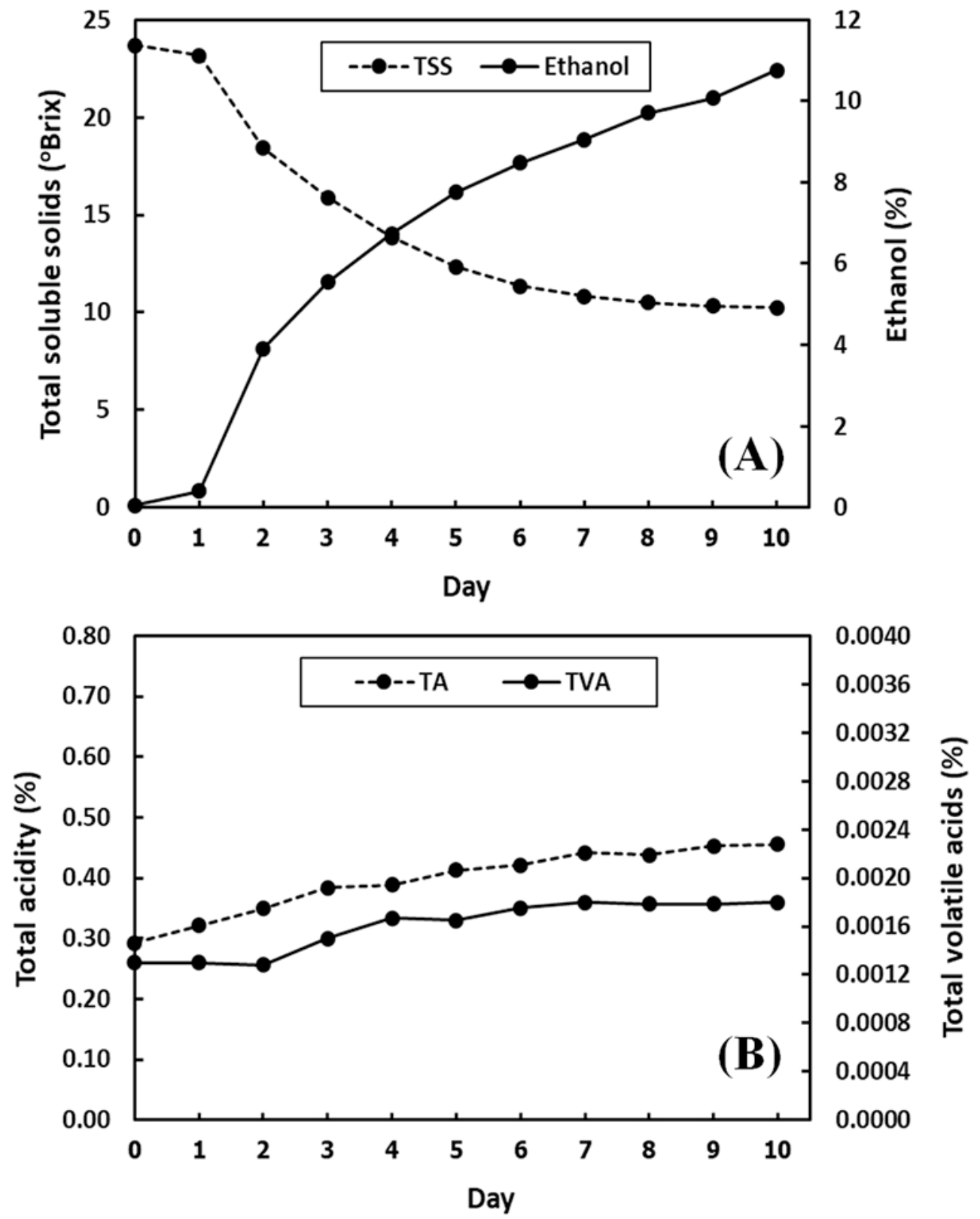

Figure 2. Monitoring of ethanol and total soluble solids (TSS) contents (A), and total acidity (TA) and total soluble solids (TVA) contents (B), for samples during the pineapple wine fermentation by the reference methods.

\subsection{NIR Spectra of Pineapple Wines from the Fermentation Process}

One hundred and ninety-eight of the original NIR spectra in the $11,536-3952 \mathrm{~cm}^{-1}$ region of pineapple wine samples obtained during fermentation using a liquid probe, and the eleven averaged spectra of the fermentation samples from 0 to 10 days in the whole spectral region, are shown in Figure 3A,B, respectively. A major component of pineapple wine is water. Therefore, a strong absorption band near 6900 and a saturated feature around $5000 \mathrm{~cm}^{-1}$ are assigned to the combination of $\mathrm{OH}$ symmetric and antisymmetric stretching modes, and the combination mode of the $\mathrm{OH}$ stretching and bending vibrations of water, respectively [15,37]. It is noted in Figure $3 \mathrm{~A}, \mathrm{~B}$ that the saturated spectral region in a grey bar is excluded for model development. However, the spectral changes of the samples during different days of fermentation were not clearly visible in the original NIR spectra. Thus, the second derivatives (SD) were applied to reveal the significant NIR regions in the 
11 averaged spectra of the fermentation samples from 0 to 10 days. Figure 3C,D presents the SD pretreated spectra in the $9500-5500 \mathrm{~cm}^{-1}$ range of pineapple wines for different fermentation dates. In Figure $3 C$, the SD pretreated spectra reveal the changes in NIR absorption bands around $8400,6800,5900,5750$, and $5650 \mathrm{~cm}^{-1}$ increased with fermentation time. Moreover, two dominant absorption bands can be seen near 4450 and $4340 \mathrm{~cm}^{-1}$ in the SD pretreated spectra of $4600-4000 \mathrm{~cm}^{-1}$ region that changed by increasing the fermentation time (Figure 3D). The absorption bands from ethanol production during the wine fermentation were previously reported in the $6060-5715$ and $4545-4350 \mathrm{~cm}^{-1}$ spectral regions $[13,38,39]$. The former was due to the $\mathrm{C}-\mathrm{H}$ stretch first overtones of the $\mathrm{CH}_{3}$ and $\mathrm{CH}_{2}$ groups, and the latter was assigned to the $\mathrm{C}-\mathrm{H}$ stretch and $\mathrm{C}-\mathrm{H}$ deformation combination from the $\mathrm{CH}_{3}$ group of ethanol $[13,38,39]$. The changes in the characteristic absorption bands observed in this study are similar to those reported by others. Therefore, they are related to characteristic bands for ethanol production from wine fermentation.
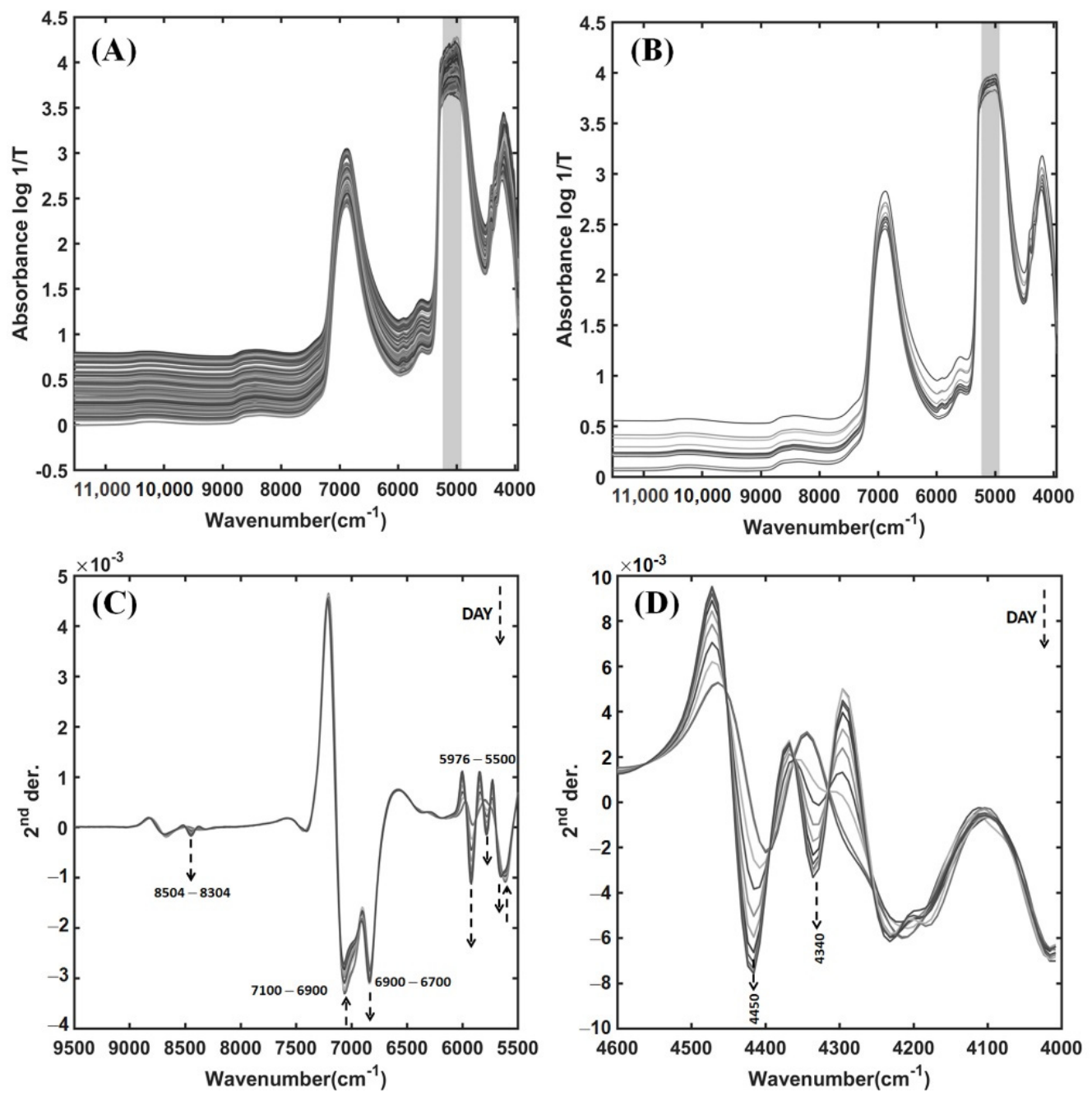

Figure 3. A total of 198 original NIR spectra in the $11,536-3952 \mathrm{~cm}^{-1}$ region of the pineapple wines during the fermentation process (A), 11 of the mean spectra of the fermentation samples from 0 to 10 days in the whole spectral region (B), and after performing second derivatives (SD) in the 9500-5500 (C) and 4600-4000 $\mathrm{cm}^{-1}$ spectral regions (D).

There are absorption bands around 7056 and $5610 \mathrm{~cm}^{-1}$ that decreased with fermentation time (Figure $3 \mathrm{C}$ ). They were assigned to the $\mathrm{O}-\mathrm{H}$ stretch first overtone and $\mathrm{C}-\mathrm{H}$ stretch first overtone, respectively, which are characteristic bands for sugars [40,41]. The sugar contents are expressed by means of the TSS value. It is because the sugar contents 
are the highest among soluble solids dissolved in a pineapple wine sample. The characteristic bands for sugars decrease with fermentation time, corresponding to the process by which yeast converts sugars to ethanol. Furthermore, the functional groups of sugars and starch for the O-H stretch first overtone (6500 to $\left.6300 \mathrm{~cm}^{-1}\right), \mathrm{C}-\mathrm{H}$ stretch first overtone (5903 to $5650 \mathrm{~cm}^{-1}$ ), O-H stretch and $\mathrm{C}-\mathrm{O}$ stretch combinations, and $\mathrm{C}-\mathrm{H}$ combinations of stretch and deformation (4504 to $4250 \mathrm{~cm}^{-1}$ ) are expected to appear in the NIR spectra of pineapple wine (Table 5) [40,41]. In Figure 3C,D, the characteristic of changes involving such expected bands are found to increase in absorption over the time of fermentation. Although the sugar contents should be greatly reduced by yeast for ethanol production in pineapple winemaking, the contents of glucose and fructose are also increased by the enzyme invertase found in the growth phase of the yeast [35]. Therefore, the NIR spectra may convey two opposite directions of sugar changes due to the fermentation pathway by yeast.

Table 5. The band assignments of significant NIR regions with absorption changes during pineapple wine fermentation from the second derivative pretreated spectra ${ }^{a}$.

\begin{tabular}{|c|c|c|}
\hline Wavenumber $\left(\mathrm{cm}^{-1}\right)$ & Band Assignment & Substance $[40,41]$ \\
\hline $8900-8504$ & $\mathrm{O}-\mathrm{H}$ & Water [37] \\
\hline $8504-8304^{b}$ & $\mathrm{C}-\mathrm{H}$ stretch 2 nd overtones of $-\mathrm{CH}_{3},-\mathrm{CH}_{2}$ & Ethanol, Sugars, Citric acid, Acetic acid \\
\hline $7100-6900^{b}$ & $\mathrm{O}-\mathrm{H}$ stretch 1 st overtones & Sugars \\
\hline $6900-6700^{b}$ & $\mathrm{O}-\mathrm{H}$ stretch 1 st overtones & Ethanol (primary alcohols), Starch \\
\hline $6896^{b}$ & $\mathrm{C}=\mathrm{O}$ stretch 1 st overtones from carbonyl group & Citric acid, Acetic acid \\
\hline 6850 & $\mathrm{O}-\mathrm{H}$ & Water [36] \\
\hline $6500-6300$ & $\mathrm{O}-\mathrm{H}$ stretch 1 st overtones & Starch \\
\hline $5976-5500^{b}$ & $\mathrm{C}-\mathrm{H}$ stretch 1 st overtones of $-\mathrm{CH}_{3},-\mathrm{CH}_{2}$ & $\begin{array}{c}\text { Ethanol }[13,38,39,42] \\
\text { Sugars, Citric acid, Acetic acid }\end{array}$ \\
\hline $4504-4250^{b}$ & $\begin{array}{l}\mathrm{C}-\mathrm{H} \text { combinations of stretch and deformation } \\
\text { from the } \mathrm{CH}_{3} \text { group }\end{array}$ & Ethanol $[13,38,39,42,43]$ \\
\hline $4504-4250^{b}$ & $\begin{array}{c}\text { O-H stretch and } \mathrm{C}-\mathrm{O} \text { stretch combinations, } \mathrm{C}-\mathrm{H} \\
\text { combinations of stretching and } \\
\text { deformation }\end{array}$ & Sugars [43], Glucose, Cellulose, Starch \\
\hline $4504-4250^{b}$ & $\mathrm{C}-\mathrm{H}$ stretch and $\mathrm{C}=\mathrm{O}$ stretch combinations & Citric acid, Acetic acid \\
\hline
\end{tabular}

Acidity in wine is expressed as the concentration of acids present, namely citric acid (TA) and acetic acid (TVA). From the literature, the chemical structures of both acids for the $\mathrm{C}-\mathrm{H}$ stretch first overtone, $\mathrm{C}-\mathrm{H}$ stretch second overtone, and $\mathrm{C}-\mathrm{H}$ stretch and $\mathrm{C}=\mathrm{O}$ stretch combinations are expected to appear in the spectral regions of 8504 to 8304, 5952 to 5600 , and 4504 to $4200 \mathrm{~cm}^{-1}$, respectively [40,41]. Although the TA and TVA values increased over the fermentation time as shown in Figure 2B, the NIR bands involve the functional groups of the major constituents in pineapple wine, i.e., water, ethanol, and sugars, which also appeared around these areas as well. The major constituents in wine exhibited the dominant NIR bands where there may be overlap with the acid bands. It is because pineapple wine in the fermentation process has very low concentrations of citric acid $(<0.5 \%)$ and acetic acid $(<0.002 \%)$ (Table 2$)$. Hence, the individual spectral regions associated with the citric and acetic acids cannot be clearly identified in the original and SD pretreated NIR spectra of pineapple wines. The NIR band assignments from the SD pretreated spectra of pineapple wine during the fermentation process are summarized in Table 5. 


\subsection{SCMWPLS Analysis}

The original NIR data after performing the SD method were employed in the MWPLSR calculations for searching for the informative spectral regions for ethanol, TSS, TA, and TVA in pineapple wine spectra. The residue lines for ethanol, TSS, TA, and TVA obtained by MWPLSR for the whole NIR spectral region of $11,536-3952 \mathrm{~cm}^{-1}$ are shown in Figure 4A-D, respectively. In residual line spectra, each line represents a certain number of LVs. The top line shows the $\log (\mathrm{SSR})$ values of the first LV model, and then the LV model increases accordingly in the following lines. In this study, the maximum LVs number was set to $10 \mathrm{LVs}$, resulting in a total of 10 lines of the residual spectra. It is noted in Figure 4 that the saturated spectral region in a grey bar is excluded for model development.
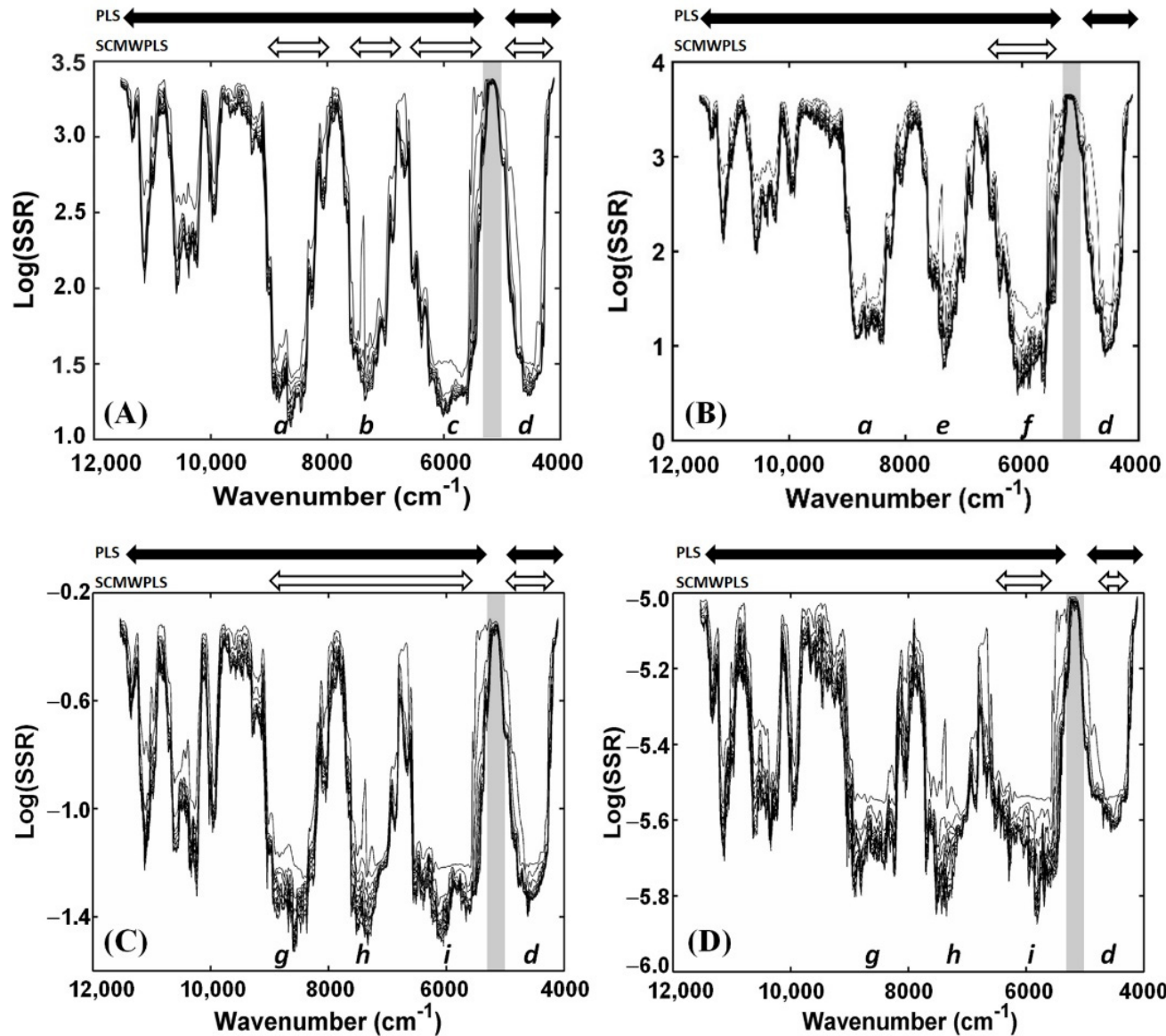

Figure 4. Residue lines for ethanol (A), total soluble solids (B), total acidity (C), and total volatile acids (D), obtained by MWPLSR using second derivative spectral data.

Figure 4A shows the four obtained informative spectral regions of 9200-8000 (a), 7800-6800 (b), 6720-5256 (c), and 4976-4008 (d) $\mathrm{cm}^{-1}$ for ethanol calculated by MWPLSR. They correspond to the second $(a)$ and first $(b, c)$ overtones, and combination bands $(d)$ from the functional groups of ethanol, respectively (Table 5 ). These informative spectral regions discovered by MWPLSR can easily be seen to encompass those bands assigned for ethanol from the SD pretreated spectra of pineapple wine samples (Figure 3C,D).

Four informative spectral regions of 9200-8000 (a), 7800-6904 (e), 6848-5256 (f), $4976-4008(d) \mathrm{cm}^{-1}$ for TSS found by MWPLSR, are shown in Figure 4B. All informative spectral regions of $a, e, f$, and $d$ for TSS cover the band assignments for sugars and related compounds given in Table 5. In Figure 4A,B, the third overtone bands for the 11,536 to $9800 \mathrm{~cm}^{-1}$ spectral region for ethanol and TSS show obviously high residue values (approximately $>2.3$ ) from the residual spectral lines of two LVs. This line is the starting point for the suitability of the model dimensions built in this region, i.e., the fitness of 
residual lines is considering the line, showing the residue values decrease insignificantly as the number of LVs increases. Therefore, this third overtone spectral region was omitted in the optimization by SCMWPLS due to less spectral information of ethanol and TSS for the model developments.

Figure 4C,D presents the same for four informative spectral regions of 9400-7904 $(\mathrm{g})$, 7896-6808 (h), 6800-5256 (i), and 4976-4008 (d) $\mathrm{cm}^{-1}$ for TA and TVA obtained by MWPLSR. The NIR band assignments that fall in these four informative spectral regions found by MWPLSR are described in Table 5. Although the individual spectral regions associated with both acids cannot be identified in the original and SD pretreated NIR spectra of pineapple wines, MWPLSR can suggest using the informative spectral regions of $g, h, i$, and $d$ for both acids with the low SSR values. The sharp peaks around 11,536-9800 $\mathrm{cm}^{-1}$ of the residual line spectra for TA and TVA show the residue values at the last line (10 LVs) close to those values obtained from the four informative spectral regions $(g, h, i, d)$. However, the residual lines can be fitted from two LVs in this region where they have higher SSR values than those given by the selected informative regions of $g, h, i$, and $d$ (Figure $4 \mathrm{C}, \mathrm{D}$ ). Therefore, this spectral region of $11,536-9800 \mathrm{~cm}^{-1}$ is not chosen as the informative spectral region for TA and TVA. It is then excluded for optimization by SCMWPLS. For the informative spectral regions of ethanol, TSS, TA, and TVA obtained by MWPLSR, the SCMWPLS algorithm was performed to search for the optimized spectral regions.

\subsection{Comparison of PLS Calibration Models}

Statistical results for ethanol, TSS, TA, and TVA models developed by using the whole spectral region in both the original and SD pretreated NIR data and the optimized informative region obtained from SCMWPLS are compared in Table 6. In all cases, the spectral region from 5248 to $4984 \mathrm{~cm}^{-1}$, where the saturate water band is located, was removed.

Table 6. Statistics results for PLS calibration models of ethanol, TSS, TA, and TVA contents for pineapple wine in fermentation developed using uncorrected spectrum or second derivative corrected spectrum in the whole regions and those regions selected by SCMWPLS.

\begin{tabular}{|c|c|c|c|c|c|c|c|c|}
\hline Parameters & Methods & Preprocessing & LVs & $R^{2}$ & RMSEC & RMSEP & RPD & $\begin{array}{c}\text { Spectral } \\
\text { Data Points }\end{array}$ \\
\hline \multirow{4}{*}{ Ethanol (\%) } & PLS & none & 4 & 0.973 & 0.588 & 0.466 & 7.36 & 915 \\
\hline & PLS & $\mathrm{SD}$ & 4 & 0.985 & 0.438 & 0.406 & 8.44 & 901 \\
\hline & SCMWPLS $\left(\mathrm{cm}^{-1}\right)$ & & & & & & & \\
\hline & $\begin{array}{l}9104-7984,7752-6704, \\
6600-5256,4976-4008\end{array}$ & SD & 3 & 0.984 & 0.457 & 0.393 & 8.72 & 564 \\
\hline \multirow{3}{*}{$\operatorname{TSS}\left({ }^{\circ}\right.$ Brix $)$} & PLS & none & 5 & 0.997 & 0.269 & 0.441 & 10.47 & 915 \\
\hline & PLS & $\mathrm{SD}$ & 2 & 0.995 & 0.330 & 0.219 & 21.08 & 901 \\
\hline & $\begin{array}{c}\text { SCMWPLS }\left(\mathrm{cm}^{-1}\right) \\
6800-5360\end{array}$ & SD & 2 & 0.996 & 0.286 & 0.166 & 27.82 & 181 \\
\hline \multirow{4}{*}{ TA $(\%)$} & PLS & none & 2 & 0.883 & $0.174 \times 10^{-1}$ & $0.182 \times 10^{-1}$ & 3.15 & 915 \\
\hline & PLS & SD & 2 & 0.892 & $0.167 \times 10^{-1}$ & $0.199 \times 10^{-1}$ & 2.88 & 901 \\
\hline & SCMWPLS $\left(\mathrm{cm}^{-1}\right)$ & & & & & & & \\
\hline & $\begin{array}{l}9200-5408 \\
4976-4008\end{array}$ & SD & 2 & 0.894 & $0.166 \times 10^{-1}$ & $0.181 \times 10^{-1}$ & 3.17 & 597 \\
\hline \multirow{3}{*}{ TVA (\%) } & PLS & none & 6 & 0.776 & $0.112 \times 10^{-3}$ & $0.117 \times 10^{-3}$ & 2.56 & 915 \\
\hline & PLS & SD & 5 & 0.753 & $0.118 \times 10^{-3}$ & $0.113 \times 10^{-3}$ & 2.65 & 901 \\
\hline & $\begin{array}{c}\text { SCMWPLS }\left(\mathrm{cm}^{-1}\right) \\
6504-5280,4504-4248\end{array}$ & SD & 6 & 0.761 & $0.116 \times 10^{-3}$ & $0.105 \times 10^{-3}$ & 2.86 & 187 \\
\hline
\end{tabular}

Whole region for PLS = 11536-5256, 4976-3952 cm $\mathrm{cm}^{-1}$; SD = second derivatives; LVs = number of latent variables; $R^{2}=$ coefficient of determination; RMSEC = root mean squares error of calibration; RMSEP = root mean squares error of prediction; RPD = Residual predictive deviation.

The acceptable NIR models should show high $R^{2}$ and RPD values and low RMSEC and RMSEP values. In addition, the best model for each analyte could be evaluated after performing the validation method by using an external test set. Therefore, the model gives the lowest RMSEP and the highest RPD, and it is the better model. The interpretation of $R^{2}$ 
and RPD values qualify a model as good for screening with an $R^{2}$ of 0.66 to 0.81 or RPD > 3 , good for quality control with an $R^{2}$ of 0.83 to 0.90 or RPD $>5$, and excellent for all analytical tasks with an $R^{2}>0.91$; RPD $>8$ [41].

It can be seen from Table 6 that the PLS calibration model for ethanol obtained using the whole spectral region yields the lowest predictability among the prediction results for ethanol. PLS prediction results for ethanol using the whole spectral region of the original NIR spectral data are an RMSEP of $0.466 \%$ and an RPD of 7.36 at 4 LVs, while the model base on the whole spectral region after performing SD pretreatment gives a better prediction model with the lower RMSEP of $0.406 \%$, a higher RPD of 8.44 at four LVs. Moreover, the SCMWPLS coupled with the SD pretreatment provides the optimized combination of 9104-7984, 7752-6704, 6600-5256, and 4976-4008 $\mathrm{cm}^{-1}$ regions. This optimized combination provides very good prediction results with the lowest RMSEP of $0.393 \%$, the highest RPD of 8.72 , and a high $R^{2}$ of 0.984 with three LVs. These results are reasonably better than those calculated by using the whole spectral regions.

For TSS, the PLS prediction results of using the whole spectral region of the original NIR spectral data are an RMSEP of $0.441 \%$ and an RPD of 10.47 at five LVs, while the whole spectral region after performing SD pretreatment shows significant improvements with a lower RMSEP of $0.219 \%$ and a higher RPD of 21.08 at two LVs. In total, the MWPLSR suggested four individual informative spectral regions for TSS in the SD pretreated NIR spectra (Figure 4B). After performing SCMWPLS for these four informative regions, one spectral region of $6800-5360 \mathrm{~cm}^{-1}$ that provided the best prediction results, with the lowest RMSEP of $0.166^{\circ}$ Brix and the highest RPD of 27.82 with two LVs, was revealed. SCMWPLS improves the RMSEP and RPD values significantly, and the number of LVs is clearly reduced.

By comparison of the results listed in Table 6, one can find that the predictive performance of models for TA and TVA are lower than those models for ethanol and TSS predictions. The quality of models for TA and TVA can be classified as good for quality control $\left(R^{2}>0.88\right.$; averaged RPD $\left.=3.07\right)$ and good for screening $\left(R^{2}>0.75\right.$ averaged $\mathrm{RPD}=2.69$ ), respectively. This was caused by the low concentrations of citric acid (TA) and acetic acid (TVA) in pineapple wine from the fermentation process. In addition, the concentration range and standard deviation of both acids are narrow, with $0.2880-0.4757 \%$ and 0.0514 of the SD for citric acid (TA), and $0.0011-0.0019 \%$ and 0.0002 of the SD for acetic acid (TVA). However, the best result for the calibration model of TA is obtained from the optimized combination of 9200-5408 and 4976-4008 $\mathrm{cm}^{-1}$ regions generated by SCMWPLS. It achieves improvement with the lowest RMSEP of $0.0181 \%$ and the highest RPD of 3.17 at two LVs. As for TVA, the optimized combination generated by SCMWPLS is composed of the $6504-5280$ and $4504-4248 \mathrm{~cm}^{-1}$ regions. The optimized combination provides the best prediction result with the lowest RMSEP of $0.000105 \%$ and the highest RPD of 2.86 with two LVs.

One can see in Table 6 that the best models obtained by SCMWPLS could reduce the NIR spectral data points for model development. The smallest NIR spectral data were 181 points for building the TSS calibration model and the highest NIR spectral data were 597 points for the modelling of TA. The simultaneous monitoring of all four chemical changes could be performed by setting the spectral acquisition for the FT-NIR spectrometer to 616 spectral points (9200-5256 and 4976-4008 $\mathrm{cm}^{-1}$ ), in which these wavenumber variables cover the optimized region for all constituents found by SCMWPLS. Then, the measurement time will become faster than collecting the NIR spectral data for the whole region (915 spectral points).

Figure 5 shows the NIR predicted and reference values of the independent test set versus the fermentation time using the best NIR models for ethanol, TSS, TA, and TVA obtained from SCMWPLS. The best predictive result is obtained from the calibration model for TSS prediction, where the NIR-predicted values did not differ from the references detected by a conventional method. This can be seen from the cross symbol showing the NIR 
prediction values overlaid with the circle symbol showing the reference values (Figure 5B).
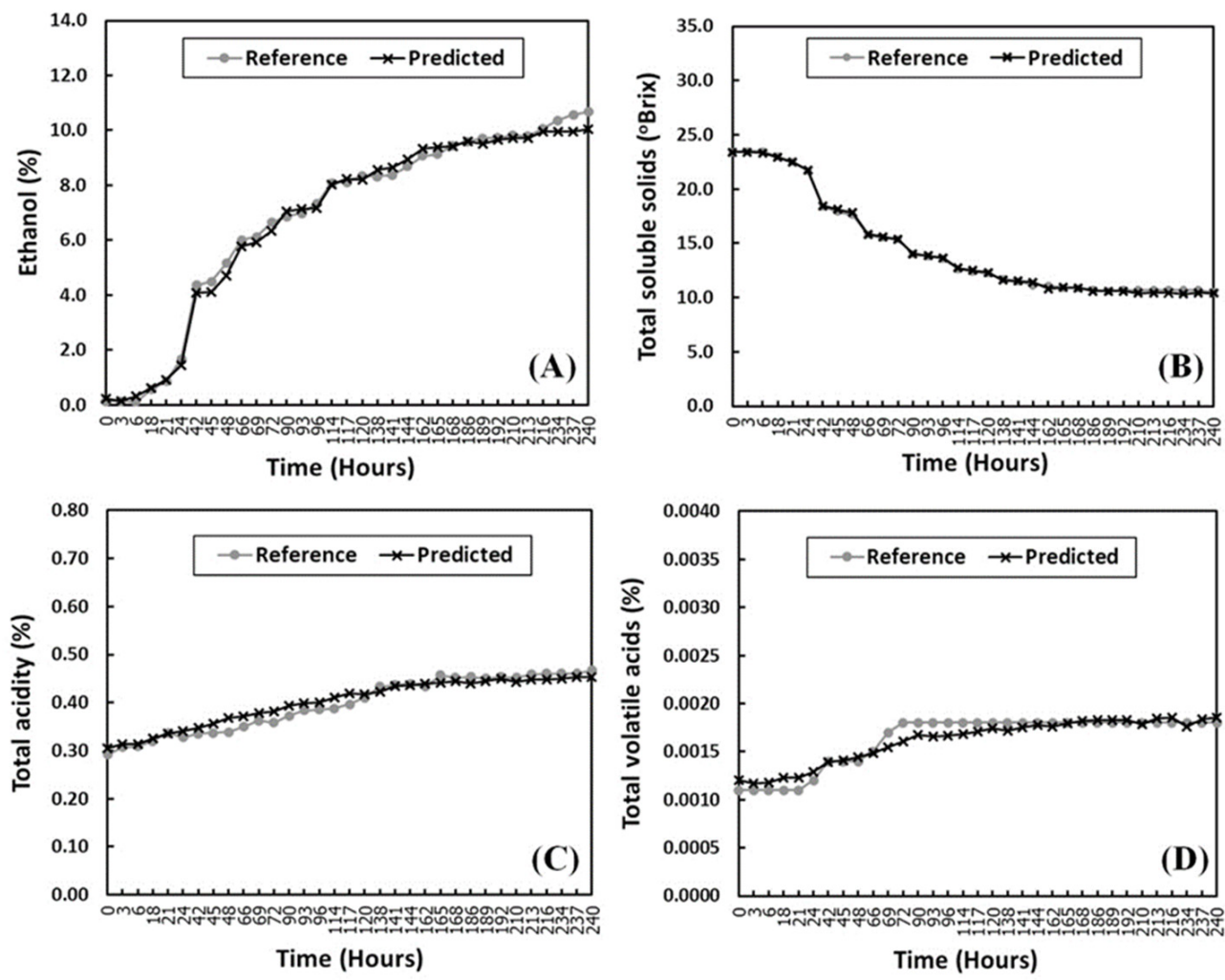

Figure 5. Comparison of quantitative analysis results for ethanol (A), TSS (B), TA (C), and TVA (D) in pineapple wine following the fermentation time by the best NIR models using SCMWPLS and the reference methods.

The NIR prediction results calculated by the best models for ethanol prediction built by the use of optimized spectral region found by SCMWPLS also yield accurate results. However, a distinct difference between the reference values and the NIR prediction occurs during 234 to $240 \mathrm{~h}$ of fermentation (Figure 5A). It was almost the end of the fermentation process at this time, in which the ethanol production should be nearly constant. The NIR prediction value seems to show a more realistic change than the reference at this point. For TA and TVA, the prediction results obtained from the best models showed lower accuracy than the TSS and ethanol prediction results. Figure 5C,D shows the apparent difference between the reference and NIR predictive values of TA and TVA that occurred approximately from 48 to $114 \mathrm{~h}$ and around 18 and 69 to $96 \mathrm{~h}$ of fermentation, respectively. The reason may be that this period shows a high rate of ethanol production. As can be seen in Figure 5A, ethanol content gradually increases after $18 \mathrm{~h}$ and then increases rapidly from 24 to $114 \mathrm{~h}$. Conversely, the TSS values show a corresponding decrease at the same time (Figure 5B). Therefore, both ethanol and $\mathrm{CO}_{2}$ are rapidly abundant in the fermentation sample. They can interfere with the observed NIR information due to the citric and acetic acids, and this may result in low accuracy for TA and TVA predictions at this period.

To assure the predictive performance of the best NIR models built by the optimized region from SCMWPLS, the bias confidence limits $\left(T_{b}\right)$ and the unexplained error confidence limits $\left(T_{\mathrm{UE}}\right)$ were also employed as an indicator of NIR predictions in this study. The validation process through an independent test set provided the SEP and bias values, which should be compared with the calculated $T_{\mathrm{UE}}$ and $T_{b}$ values, respectively. When both the SEP and bias values were below these two confidence limits (SEP $<T_{\mathrm{UE}}$; bias $< \pm T_{b}$ ), this NIR model is considered to be accepted for its performance. The statistical results for the performance evaluation of the best models are summarized in Table 7 . There is no 
doubt regarding an accurate predictive performance for ethanol and TSS models as the results show above. However, this statistical analysis was specially employed because the efficiency of the best models for TA and TVA should be taken into account. From Table 7, it can be seen that the statistical results obtained from the best models for TA and TVA also met the criteria. The interpretations of this result are that the SEP value is low enough to make it practically acceptable when it was lower than the calculated $T_{\mathrm{UE}}$ value, and the bias value was not significantly different from zero when it was lower than that calculated $\pm T_{b}$.

Table 7. Statistics for assessment of the model performance.

\begin{tabular}{ccccc}
\hline $\begin{array}{c}\text { NIR Models by } \\
\text { SCMWPLS }\end{array}$ & Statistics & Obtained Results & Criterion & Performance \\
\hline \multirow{2}{*}{ Ethanol $(\%)$} & SEP & 0.374 & $T_{\mathrm{UE}}=0.554$ & accepted \\
& Bias & 0.128 & $T_{b}= \pm 0.132$ & accepted \\
\hline \multirow{2}{*}{ TSS $\left({ }^{\circ}\right.$ Brix) } & SEP & 0.164 & $T_{\mathrm{UE}}=0.346$ & accepted \\
& Bias & 0.029 & $T_{b}= \pm 0.058$ & accepted \\
\hline \multirow{2}{*}{ TA $(\%)$} & SEP & $0.175 \times 10^{-1}$ & $T_{b}= \pm 0.006$ & accepted \\
& Bias & 0.005 & $T_{\mathrm{UE}}=0.140 \times 10^{-3}$ & accepted \\
\hline \multirow{2}{*}{ TVA $(\%)$} & SEP & $0.105 \times 10^{-3}$ & $T_{b}= \pm 0.037 \times 10^{-3}$ & accepted \\
& Bias & $0.012 \times 10^{-3}$ & accepted \\
\hline
\end{tabular}

$T_{\mathrm{UE}}=$ unexplained error confidence limits $(\alpha=0.05) ; T_{b}=$ bias confidence limits $(\alpha=0.05)$.

\section{Conclusions}

The results of present study demonstrated the potential of NIR spectroscopy coupling with SCMWPLS to enhance the predictive performance of NIR calibration models for simultaneously monitoring the changes in ethanol, total soluble solids, total acidity, and total volatile acids in pineapple fruit wine during the fermentation process. SCMWPLS could select and optimize informative spectral regions from the second derivative spectra of very complicated mixtures such as wine obtained by the FT-NIR fibre optic probe. The optimized informative regions are the combination of 9104-7984, 7752-6704, 6600-5256, and $4976-4008 \mathrm{~cm}^{-1}$ regions for ethanol, the $6800-5360 \mathrm{~cm}^{-1}$ region for TSS, the combination of 9200-5408 and 4976-4008 $\mathrm{cm}^{-1}$ regions for TA, and the combination of 6504-5280 and $4504-4248 \mathrm{~cm}^{-1}$ regions for TVA. The quality of their PLS calibrations is improved in comparison with those obtained using the whole region. Furthermore, the present study has verified the advantages of the NIR liquid probe in combination with SCMWPLS for direct NIR measurements in pineapple wines from the fermentation process without sample preparation. Therefore, the best models obtained from these tools provided good prediction results with acceptable statistics and especially the use of a small number of spectral data points that will make faster NIR measurement possible. However, further cases or device designs for liquid probe measurement should be considered to protect the probe from being disturbed by the $\mathrm{CO}_{2}$ and microparticles (if the interference has a particle size smaller than the probe slit $<1 \mathrm{~mm}$ ) found in the fermentation system in order to stabilize the NIR signal and improve the prediction of low-concentration constituents.

Author Contributions: Conceptualization, funding acquisition, supervision and writing-original draft preparation, S.K.; conceptualization, fermentation methodology, and investigation, A.B.; K.N. is an engineer who contributed to the setup of the NIR experiment, validation process, and software; review and editing original draft preparation and project administration, S.J.; formal analysis and performed methodology, W.A., P.J. and J.M.; resource and visualization, P.V. All authors have read and agreed to the published version of the manuscript.

Funding: This research was funded by the Kasetsart University Research and Development Institute (KURDI), grant number FF(KU)15.64.

Institutional Review Board Statement: Not applicable. 
Informed Consent Statement: Not applicable.

Data Availability Statement: The data presented in this study are available in the article.

Acknowledgments: S.K. gratefully thanks Warapa Mahakarnchanakul (Food Science and Technology Department, Faculty of Agro-Industry, Kasetsart University) and the KURDI committee for valuable discussion and comments.

Conflicts of Interest: The authors declare no conflict of interest.

\section{References}

1. Pino, J.A.; Queris, O. Analysis of volatile compounds of pineapple wine using solid-phase microextraction techniques. Food Chem. 2010, 122, 1241-1246. [CrossRef]

2. Shahbandeh, M. Leading Countries in Pineapple Production Worldwide in 2019. Available online: https://www.statista.com/ statistics/298517/global-pineapple-production-by-leading-countries/\#statisticContainer (accessed on 13 March 2021).

3. Dellacassa, E.; Trenchs, O.; Fariña, L.; Debernardis, F.; Perez, G.; Boido, E.; Carrau, F. Pineapple (Ananas comosus L. Merr.) wine production in Angola: Characterisation of volatile aroma compounds and yeast native flora. Int. J. Food Microbiol. 2017, 241, 161-167. [CrossRef]

4. Lobo, M.G.; Yahia, E. Biology and postharvest physiology of pineapple. In Handbook of Pineapple Technology: Postharvest Science, Processing and Nutrition; Blackwell, W., Ed.; John Wiley \& Sons, Ltd.: Hoboken, NJ, USA, 2016; pp. 39-61.

5. Mohd-Ali, M.; Hashim, N.; Aziz, S.A.; Lasekan, O. Pineapple (Ananas comosus): A comprehensive review of nutritional values, volatile compounds, health benefits, and potential food products. Food Res. Int. 2020, 137, 109675. [CrossRef] [PubMed]

6. Cannon, R.J.; Ho, C.T. Volatile sulfur compounds in tropical fruits. J. Food Drug Anal. 2018, 26, 445-468. [CrossRef] [PubMed]

7. Otegbayo, B.O.; Akwa, I.M.; Tanimola, A.R. Physico-chemical properties of beetroot (Beta vulgaris 1.) wine produced at varying fermentation days. Sci. Afr. 2020, 8, e00420. [CrossRef]

8. Margalit, Y. Must and wine composition. In Concepts in Wine Chemistry; Wine Appreciation Guild: San Francisco, CA, USA, 2004; pp. 1-59.

9. Waterhouse, A.L.; Sacks, G.L.; Jeffery, D.W. Introduction. In Understanding Wine Chemistry; John Wiley \& Sons: Hoboken, NJ, USA, 2016; pp. xvii-xxiv.

10. Alañón, M.E.; Pérez-Coello, M.S.; Marina, M.L. Wine science in the metabolomics era. Trends Anal. Chem. 2015, 74, 1-20. [CrossRef]

11. Teixeira dos Santos, C.A.; Páscoa, R.N.M.J.; Lopes, J.A. A review on the application of vibrational spectroscopy in the wine industry: From soil to bottle. Trends Anal. Chem. 2017, 88, 100-118. [CrossRef]

12. Cozzolino, D. Sample presentation, sources of error and future perspectives on the application of vibrational spectroscopy in the wine industry. J. Sci. Food Agric. 2015, 95, 861-868. [CrossRef]

13. Cozzolino, D.; Kwiatkowski, M.J.; Parker, M.; Cynkar, W.U.; Dambergs, R.G.; Gishen, M.; Herderich, M.J. Prediction of phenolic compounds in red wine fermentations by visible and near infrared spectroscopy. Anal. Chim. Acta 2004, 513, 73-80. [CrossRef]

14. Martelo-Vidal, M.J.; Vázquez, M. Determination of polyphenolic compounds of red wines by UV-VIS-NIR spectroscopy and chemometrics tools. Food Chem. 2014, 158, 28-34. [CrossRef]

15. Ozaki, Y.; Huck, C.; Tsuchikawa, S.; Engelsen, S.B. Near-Infrared Spectroscopy Theory, Spectral Analysis, Instrumentation, and Applications; Springer: Berlin/Heidelberg, Germany, 2021.

16. Burns, D.A.; Ciurczak, E.W. Handbook of Near-Infrared Analysis; Marcel Dekker: New York, NY, USA, 1992.

17. Siesler, H.W.; Ozaki, Y.; Kawata, S.; Heise, H.M. Near-Infrared Spectroscopy Principles, Instruments, Applications; WILEY-VCH: Weinheim, Germany, 2002.

18. Cozzolino, D. State-of-art advantages and drawbacks on the application of vibrational spectroscopy to monitor alcoholic fermentation (beer and wine). Appl. Spectrosc. Rev. 2016, 51, 302-317. [CrossRef]

19. Wu, Z.; Xu, E.; Wang, F.; Long, J.; Xu, X.; Jiao, A.; Jin, Z. Rapid determination of process variables of Chinese rice wine using FT-NIR spectroscopy and Efficient Wavelengths Selection Methods. Food Anal. Methods 2015, 8, 1456-1467. [CrossRef]

20. Ye, M.; Yue, T.; Yuan, Y.; Li, Z. Application of FT-NIR spectroscopy to apple wine for rapid simultaneous determination of soluble solid content, pH, total acidity, and total ester content. Food Bioprocess Technol. 2014, 7, 3055-3062. [CrossRef]

21. Peng, B.; Ge, N.; Cui, L.; Zhao, H. Monitoring of alcohol strength and titratable acidity of apple wine during fermentation using near-infrared spectroscopy. LWT-Food Sci. Technol. 2016, 66, 86-92. [CrossRef]

22. Li, G.; Yan, N.; Yuan, L.; Wu, J.; Du, J.; Gao, Y.; Peng, Y. Rapid analysis of alcohol content during the green jujube wine fermentation by FT-NIR. E3S Web Conf. IAECST 2019 2020, 145, 01037. [CrossRef]

23. Fernández-Novales, J.; María-Isabel, L.; María-Teresa, S.; José-Antonio, G.; José, M. A feasibility study on the use of a miniature fiber optic NIR spectrometer for the prediction of volumic mass and reducing sugars in white wine fermentations. J. Food Eng. 2008, 89, 325-329. [CrossRef]

24. Du, Y.P.; Liang, Y.Z.; Jiang, J.H.; Berry, R.J.; Ozaki, Y. Spectral regions selection to improve prediction ability of PLS models by changeable size moving window partial least squares and searching combination moving window partial least squares. Anal. Chim. Acta 2004, 501, 183-191. [CrossRef] 
25. Kasemsumran, S.; Du, Y.P.; Murayama, K.; Huehne, M.; Ozaki, Y. Near-infrared spectroscopic determination of human serum albumin, $\gamma$-globumin, and glucose in a control serum solution with searching combination moving window partial least squares. Anal. Chim. Acta 2004, 512, 223-230. [CrossRef]

26. Kasemsumran, S.; Du, Y.P.; Maruo, K.; Ozaki, Y. Improvement of partial least squares models for in vitro and in vivo glucose quantifications by using near-infrared spectroscopy and searching combination moving window partial least squares. Chemometr. Intell. Lab. Syst. 2006, 82, 97-103. [CrossRef]

27. Rongtong, B.; Suwonsichon, T.; Ritthiruangdej, P.; Kasemsumran, S. Determination of water activity, total soluble solids and moisture, sucrose, glucose and fructose contents in osmotically dehydratedpapaya using near-infrared spectroscopy. Agric. Nat. Resour. 2018, 52, 557-564.

28. International Federation of Fruit Juice Producers (IFU). Determination of Titratable Acidity; IFU Analysis No.3; IFU: Paris, France, 1996.

29. International Federation of Fruit Juice Producers (IFU). Determination of Total Volatile Acids; IFU Analysis No.5; IFU: Paris, France, 1968.

30. Jiang, J.H.; Berry, R.J.; Siesler, H.W.; Ozaki, Y. Wavelength interval selection in multicomponent spectral analysis by moving window partial least-squares regression with applications to mid-infrared and near-infrared spectroscopic data. Anal. Chem. 2002, 74, 3555-3565. [CrossRef]

31. Kasemsumran, S.; Du, Y.; Li, B.; Maruo, K.; Ozaki, Y. Moving window cross validation: A new cross validation method for the selection of a rational number of components in a partial least squares calibration model. Analyst 2006, 131, 529-537. [CrossRef]

32. ISO 12099:2017(E); Animal Feeding Stuffs, Cereals and Milled Cereal Products-Guidelines for Application of Near Infrared Spectrometer. ISO: Geneva, Switzerland, 2017; 5-12.

33. Singpoonga, N.; Rittiron, R.; Seang-on, B.; Chaiprasart, P.; Bantadjan, Y. Determination of Adenosine and Cordycepin Concentrations in Cordyceps militaris Fruiting Bodies Using Near-Infrared Spectroscopy. ACS Omega 2020, 5, 27235-27244. [CrossRef]

34. Sankom, A.; Mahakarnchanakul, W.; Rittiron, R.; Sajjaanantakul, T.; Thongket, T. Detection of profenofos in Chinese kale, cabbage, and chili spur pepper using fourier transform near-infrared and fourier transform mid-infrared spectroscopies. ACS Omega 2021, 40, 26404-26415. [CrossRef]

35. Marques, W.L.; Raghavendran, V.; Stambuk, B.U.; Gomber, A.K. Sucrose and Saccharomyces cerevisiae: A relationship most sweet. FEMS Yeast Res. 2016, 16, fov107. [CrossRef]

36. Okeke, B.C.; Agu, K.C.; Uba, P.O.; Awah, N.S.; Anaukwu, C.G.; Archibong, E.J.; Uwanta, L.I.; Ezeneche, J.N.; Ezenwa, C.U.; Orji, M.U. Wine production from mixed fruits (pineapple and watermelon) using high alcohol tolerant yeast isolated from palm wine. Univers. J. Microbiol. Res. 2015, 3, 41-44.

37. Maeda, H.; Ozaki, Y.; Tanaka, M.; Hayashi, N.; Kojima, T. Near infrared spectroscopy and chemometrics studies of temperaturedependent spectral variations of water: Relationship between spectral changes and hydrogen bonds. J. Near Infrared Spectrosc. 1995, 3, 191-201. [CrossRef]

38. Cozzolino, D.; Parker, M.; Dambergs, R.G.; Herderich, M.; Gishen, M. Chemometrics and visible-near infrared spectroscopic monitoring of red wine fermentation in a pilot. Biotechnol. Bioeng. 2006, 95, 1101-1107. [CrossRef]

39. Dambergs, R.G.; Kambouris, A.; Francis, I.L.; Gishen, M. Rapid analysis of methanol in grape derived distillation products using near infrared transmission spectroscopy. J. Agric. Food Chem. 2002, 50, 3079-3084. [CrossRef]

40. Workman, J.; Weyer, L., Jr. Practice Guide to Interpretive Near Infrared Spectroscopy; CRC Press: New York, NY, USA, 2007.

41. Williams, P.; Antoniszyn, J.; Manley, M. Near Infrared Technology: Getting the Best out of Light; African Sun Media, Sun Press: Stellenbosch, South Africa, 2019.

42. Beć, B.K.; Futami, Y.; Wójcik, M.; Ozaki, Y. A spectroscopic and theoretical study in the near-infrared region of low concentration aliphatic alcohols. Phys. Chem. Chem. Phys. 2016, 18, 13666-13682. [CrossRef]

43. Grassia, S.; Amigo, J.M.; Lyndgaard, C.B.; Foschino, R.; Casiraghi, E. Beer fermentation: Monitoring of process parameters by FT-NIR and multivariate data analysis. Food Chem. 2014, 155, 279-286. [CrossRef] [PubMed] 